\title{
Sports and Community on Campus: Constructing a Sports Experience That Matters
}

\author{
Stacy Warner Marlene A. Dixon
}

Student affairs personnel are often charged with the task of creating a sense of community on campuses. Sports is among the many activities that historically have been used to meet this need for community among students. Yet, how and when a sense of community is created within a sports context has not been appropriately addressed in literature. Utilizing a community psychology theoretical framework for this study, we employed a qualitative approach to uncover the necessary factors for creating a sense of community within a sports club setting. The results revealed that Common Interest, Leadership Opportunities, Voluntary Activity, and Competition were the most critical components to creating a sense of community. The results advance community building theory and suggest practical application for improving the student experience. The implications for sports managers and student affairs administrators are also discussed.

Community psychologists have suggested that there are many benefits that enhance life quality for those who find themselves inside a social group environment that fosters a sense of community (e.g., Battistich \& Hom, 1997; Chavis \& Wandersman, 1990; Davidson \& Cotter, 1991; Pretty, Andrewes, $\&$ Collett, 1994). Alternatively individuals who find themselves outside of healthy social groups experience anomie, social isolation, alienation, and the detrimental repercussions that detract from life quality. While sociologists, psychologists, and social psychologists may use different terminology to express this lack of community, a general agreement exists that individuals in the US are more frequently finding themselves on the outside of salubrious community (McPherson, Smith-Lovin, \& Brashears, 2006; Putnam, 2000). A salubrious or healthy community is defined as one in which individuals experience a strong sense of community (SOC) at the individual and collective levels (Bess, Fisher, Sonn, \& Bishop, 2002).

On college campuses, healthy community has long been a goal of administrators and student affairs personnel (Boyer, 1990). In fact, a strong sense of community on college campuses has been linked to reduced incidences of student burnout and improvements in academic performance (McCarthy, Pretty, \& Catano, 1990); yet building and maintaining a strong community has been elusive. In fact, many suggest that such community is diminishing rapidly on college campuses, following trends in the larger US population (Boyer, 1990; Putnam, 2000) where social isolation and alienation are increasing due to technological advances and increasing professional responsibilities (McPherson et al., 2006). As a result, the need for understanding how community is built and maintained is becoming increasingly important (Putnam, 2000).

Many have suggested that sports can be used to foster a SOC among individuals (e.g., Chalip, 2006; Lyons \& Dionigi, 2007;

Stacy Warner is Assistant Professor of Kinesiology at East Carolina University. Marlene A. Dixon is Associate Professor of Kinesiology and Health Education at The University of Texas at Austin. 
Mitrano \& Smith, 1990); whether or not it does, however, is contingent upon how sports programs are managed: in some cases sports can create community and in others it can actually contribute to anomie or social isolation (Chalip, 2006). The literature reveals little about what factors help foster a SOC in a sports setting. With a better understanding of how and when a sports setting fosters a SOC on university campuses, sports managers and university administrators will be able to not only justify the continued need for sports in various forms, but also play a key role in improving the life quality of their community members. The purpose of this study is to explore the factors that build a SOC among sports club participants.

\section{SENSE OF COMMUNITY}

According to Sarason (1974), who coined the term sense of community and is credited with starting the discipline of community psychology, SOC is a characteristic of communities that results in the perception of similarity, acknowledgment and willingness to maintain interdependence, and the feeling that one is part of a larger reliable and stable structure. The outcomes of such a community include increased civic participation (Chavis \& Wandersman, 1990), subjective well-being (Davidson \& Cotter, 1991), and problemfocused coping (Bachrach \& Zautra, 1985), as well as decreased loneliness (Pretty et al., 1994), drug use, and delinquent behaviors (Battistich \& Hom, 1997).

Unfortunately, the outcomes of not experiencing this type of community and SOC can have devastating impacts on an individual and the community. A lack of community has been shown to lead to deviant behavior (Hirschi, 1969) and to have potent unfavorable effects on physical and mental health (Berkman, Glass, Brissette, \& Seeman,
2000). Therefore, it is vital to explore the ways that community can be developed such that the consequences of anomie and isolation are avoided and the benefits of community experienced.

Typically, the community psychology literature has placed an emphasis on the individual level and individual outcomes of SOC rather than on the community. While community psychologists claim a focus on the environmental factors that influence SOC, only recently have studies in this area emphasized the importance that context and environment play on the creation and experience of SOC. Two scholars in particular, Hill (1996) and Puddifoot (1996), have strongly asserted that SOC is context-specific, and therefore, it is imperative for researchers to explore the conditions and structures under which SOC develops.

Any community that is structured so that it fosters a strong psychological sense of community among its residents will most likely also be structured in such a way as to promote the healthiest possible outcomes for its residents. If we can learn what aspects of communities foster a strong psychological sense of community, and can learn to increase those aspects, perhaps we will not have to concern ourselves with specific problems and the interventions to deal with them. We could concentrate on forming healthy communities, and rely on the communities to form the healthy individuals. (Hill, 1996, p. 435)

This theoretical shift in the literature recognizes the need to place more consideration on the structures that foster SOC rather than individual outcomes.

Most of the early work on SOC has been conducted in neighborhood settings and has continued to utilize and support McMillan and Chavis's (1986) SOC theory, which contends SOC is comprised of four components: (a) membership, (b) influence, (c) integration and fulfillment of needs, and (d) emotional 
connections. Gusfield (1975), however, posited that there are two main definitions of community: the first is based on geographical and neighborhood settings, and the second is more relational and is based around a common interest or activity. A gradual shift in current SOC research has occurred as researchers have moved away from studying neighborhoods and have begun to focus more on the second type of community Gusfield described. For example, researchers have recently conducted SOC studies on university campuses and other school settings (e.g., Battistich \& Hom, 1997; Deneui, 2003), and in the workplace (Lambert \& Hopkins, 1995).

Consequently, while research within neighborhood settings has strongly supported McMillan and Chavis's (1986) theory, the research outside of such contexts has recently begun to expand the boundary conditions of their theory. For example, in a study within the workplace, Pretty and McCarthy (1991) proposed that competition impacted SOC and, more specifically, that gender differences may exist in perceptions of competition and SOC in the workplace; they suggested that competition may promote SOC for males while it detracts from SOC for females. To give another example, in a study of science fiction fans within virtual communities, researchers found that face-toface contact was not necessary to contribute to a SOC (Obst, Zinkiewicz, \& Smith, 2002a, 2002b). Such research conducted outside of traditional neighborhood settings has revealed critical findings that have contributed to and challenged McMillan and Chavis's SOC theory, while also revealing data that could have many practical applications in their respective contexts.

\section{Sports and Sense of Community in a University Context}

Sports has been embedded in the culture of American higher education for well over a century and is well positioned as a tool to create a SOC for both participants and spectators. Chu (1989) argued that the reason for this is the ability of sports "to answer a need created by our pluralistic society and to help fulfill the peculiar mission of American higher education by providing a vehicle for a sense of community, [and] promoting student commitment to the institution" (p. 158).

A need for extracurricular activities grew as a result of student response to the stringent structure of the academic environment in the early 19th century (Brubacher \& Rudy, 1997). Prior to varsity athletics, student-organized sports-based class battles (e.g., freshman vs. sophomore) and sports clubs, which were organized by students with a common interest in a given sport, were quite popular (Lewis, 1970). "Those battles on the playing field apparently filled a need for community-not just separate class unity but occasions for the entire student body to take part in an intense experience. Those who reminisced about their 19th-century college life often cited their campus sport activities" (Smith, 1988, pp. 21-22). It is obvious that sports has played a unique role in creating community for campus populations.

Class battles and sports clubs, however, began to fade in the early 20th century. Sports clubs had evolved to a point where university officials realized their educational value. Thus, they replaced informal sports clubs with formal varsity athletics and physical education (Hyatt, 1977).

While [sports clubs] contributed to a sense of community, the development of intercollegiate athletics began to replace them. As class size rose in the latter 19th century, the need for community became even more important, and [varsity] athletics played an increasingly vital role in creating it. (Smith, 1988, p. 23)

Sports provided a platform to engender community and coalesce an ever increasing 
religiously and culturally diverse student population (Chu, 1989; Smith, 1988).

It should be reiterated that at the outset class battles and sports clubs were student-run and student-initiated before evolving into varsity athletics. "Neither the faculties nor other critics assisted in building the structure of college athletics. . . It is a structure which students unaided have [built]" (Camp, 1885, p.139). Eventually extracurricular activities, including sport-based activities, were absorbed by athletic and student affairs departments. A paucity of information exists regarding sports clubs on campuses from the 1890s to the early 1960s. This is most likely due to the rapid growth of varsity athletics; however, a notable reemergence of the student-organized clubs and a "sport club movement" occurred in the 1960s (Hyatt, 1977). One rationale for the exponential increase in sports clubs on campuses was that "clubs were a reaction against highly organized, overemphasized, and rigidly specialized college and university activities, including intercollegiate [varsity] and intramural sports" (Hess, 1971, p. 24).

Today, these two distinct sports structures, sports clubs and varsity athletics, still commonly coexist on university campuses. While both represent intercollegiate athletics in that they encompass teams that compete against other colleges, the structure and administration in both systems is quite different. In brief, varsity athletics are more structured, regulated, and coach-directed, while sports clubs tend to be less structured, less regulated, and more athlete-directed. A SOC inquiry among either structure would be beneficial to administrators since little is known about how a SOC is fostered in a sports and university context.

McCormack and Chalip (1988) have argued that much of the sports literature has assumed that sporting environments are uniform or homogenous by comparing sports participants to nonparticipants and not looking at variations within these groups; that is, such studies treat all sporting environments and participant experiences as if they were consistently identical. While these studies may be productive in making general comparisons of sports participants to nonparticipants, they fail to consider the impact of the structural and environmental context in which sports are played, and do not allow comparisons of sports participant experiences within and between contexts.

Previous work (Warner \& Dixon, 2011) has already explored SOC among NCAA varsity sports participants. That investigation revealed five salient factors that contributed to SOC: (a) Administrative Consideration, (b) Leadership Opportunities, (c) Equity in Administrative Decisions, (d) Competition, and (e) Social Spaces. Warner and Dixon's (2011) results provided practical solutions for enhancing SOC and the participant experience among varsity athletes, while also contributing to SOC theory. To formulate a more generalized sports and SOC theory, it is necessary to explore other intercollegiate sports structures.

Sports is frequently considered a context that draws people together and contributes to the creation of community (Schimmel, 2003); however, the outcomes of sports are dependent upon how programs and participation are managed and structured (Chalip, 2006; Kleiber, 1983). In order to advance SOC theory and better understand the university sports experiences, we explored the factors that foster a SOC among sports club participants and the contingencies that impact SOC to provide practitioners with knowledge on how to improve the SOC experienced for sports participants.

\section{METHOD}

This study utilized a qualitative interpretive approach to data collection. This approach utilizes flexible data collection procedures and 
seeks to gain insight based on the participants' experiences, not researcher-imposed constructs (Benzies \& Allen, 2001; Jacob, 1987). This approach is useful in the case of community, because it not only allows for participants to share their experience, but also to understand how they make sense of that experience and the factors (particularly environmental) that contribute to it (Larkin, Watts, \& Clifton, 2006).

\section{Instrument}

A semi-structured interview format was used to collect data. "In terms of data collection, systems cannot be interviewed; individuals can, and they, as part of social systems, from groups to organizations, have experiences that reflect the system" (Luschen, 1986, p. 150). Thus, individuals were interviewed to gain knowledge of the system (or community) they experienced, particularly their perceptions of the factors that influenced that community.

The less formal semi-structured interview format allowed the researcher to start by asking a broad interview question and then to follow the conversation until eventually the questions became more focused (Munhall, 2007). Further, an interpretive approach suggests that some experiences are manifest, while some are more latent; thus, the interview guide was designed to elicit both. Through coding and interaction with the data, meanings and interpretations emerged that may not have been readily apparent in the questions themselves (Larkin et al., 2006). Sample guiding questions included:

- Some athletes have said they've felt a sense of community during the participation experiences. Did you ever feel that way?

- Some have said there were times when they didn't experience a sense of community. Have you ever felt that way?

- What do you think contributed to that sense (or lack) of community?
All guiding interview questions were based on and/or adapted from the community psychology literature (Deneui, 2003; Lyons \& Dionigi, 2007). Experts in sports management, community studies, and qualitative research reviewed the questions for face validity, and necessary changes were made prior to implementation for this study.

\section{Participants}

Twenty-one former college sports club athletes, representing 17 universities and 11 sports took part in the study. The participants were recent graduates (in the last 1 to 5 years) who had played on competitive intercollegiate (but not varsity) sports clubs. Former athletes were chosen because they have had time to reflect and were able to speak to experiences that resonate beyond college and not just proximal events. The sample was balanced in terms of gender (10 females, 11 males). Purposeful sampling was used to ensure that a variety of perspectives and experiences were probed in order to achieve maximum variation (Miles \& Huberman, 1994). Such sampling assists researchers during the coding as they look to uncover patterns that would be consistent with a variety of participants.

\section{Procedure}

Participants were contacted through directors of sports club programs at universities across the United States. Phone interviews were conducted and digitally recorded with those who indicated that they were willing to participate in the study. Prior to the interviews the participants were contacted and asked for their voluntary written consent. Arrangements were made to conduct the interviews at convenient times for the participants.

\section{Data Analysis}

The interviews were transcribed, and participants were given the chance to review their 


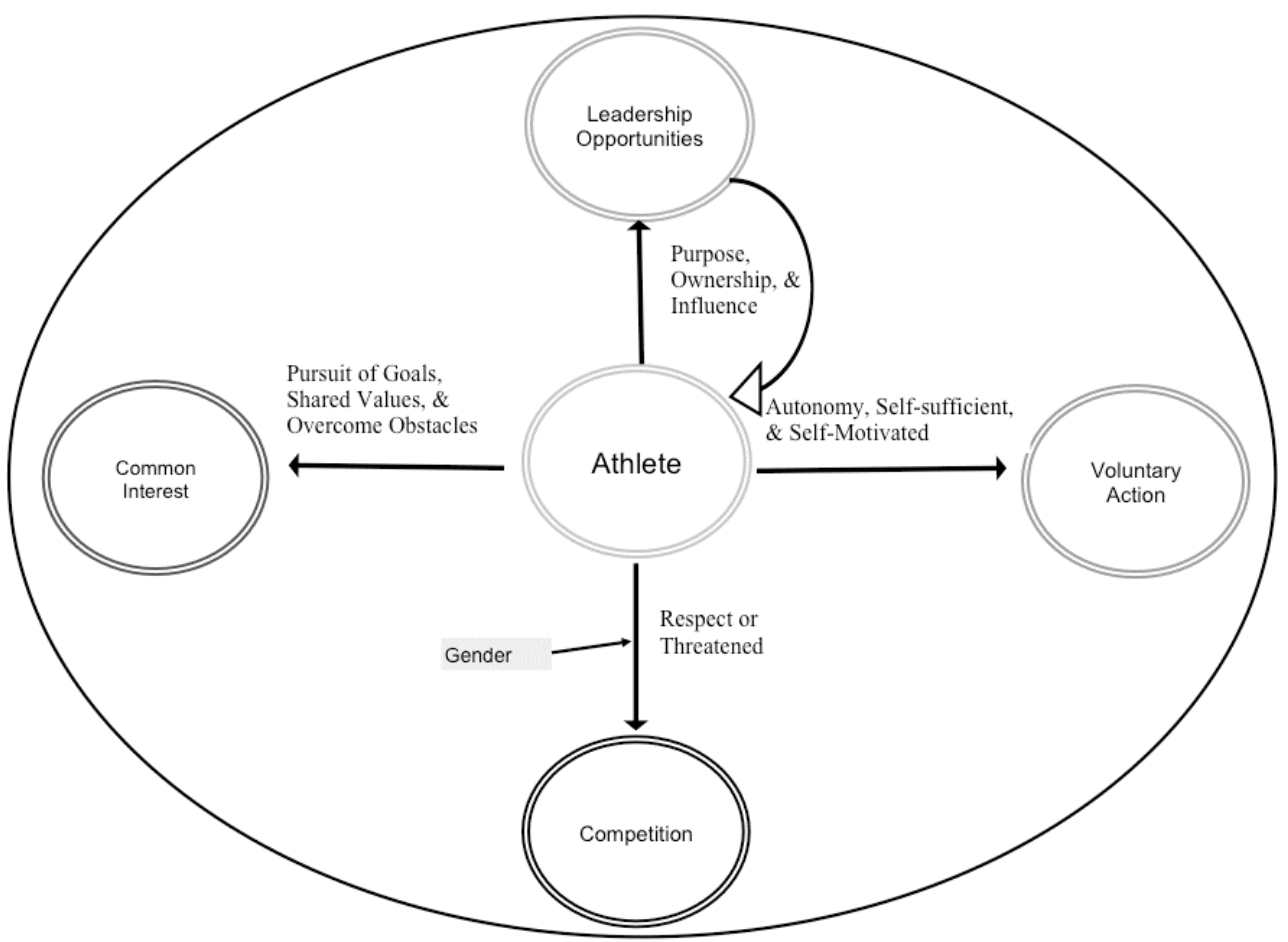

FIGURE 1. Factors Contributing to Sense of Community (SOC) for Sports Club Participants

transcripts for accuracy. The data were analyzed with the aid of NVivo 8 software. The researcher initially coded the data line by line; this process entails assigning codes or labels to the data in an attempt to condense the data into categories. Consistent with an interpretive approach, while aware of the existing literature, during the coding we were open to the emergence of new codes and fresh insights (Larkin et al., 2006; Sandelowski, 1993). The first step involved the inductive identification of salient codes that described and represented the participants' experiences and the interpretation of those experiences in light of our objectives. For example, as participants described their experiences with their teams, such concepts as "having influence," "being a leader," "being given a sense of ownership" emerged in the data and were coded according to those terms. The codes were then grouped into descriptive categories (Munhall, 2007). For example, the above codes were combined to create the theme Leadership Opportunities. Both codes and themes were cross-checked between the members of the research team for meaning and interpretation. Finally, it is important in interpretive research to make sure that the interpretation is authentic and meaningful to the participants and that the researcher has not imposed inaccurate or irrelevant terminology or interpretive frameworks on the participants' experiences (Larkin et al., 2006). Therefore, member checks for interpretations and conclusions drawn were conducted with the participants to further ensure the trustworthiness of the data and address these concerns (Munhall, 2007). 


\section{RESULTS}

The emergent results revealed that four salient factors contributed to the cultivation of a SOC for the participants: Common Interest, Leadership Opportunities, Voluntary Activity, and Competition. In Figure 1 the arrows from the athlete to the factors are labeled with a description of the action or mechanism through which the factors fostered a SOC.

\section{Common Interest}

The group dynamics, social networks, and friendships that resulted from individuals being brought together by the common interest and working towards a common goal were salient factors in producing a SOC. As Brad (a lacrosse player) explained, "We used to say, 'You don't have to like them, but you have to love them'-' cause they're your teammates. Certainly just having a team or an organization that's focusing on a goal and the objectives to get to that goal really helps build that sense of community." Common interest in sports when combined with the pursuit of team goals, which included performances both on and off the field, impacted the creation of SOC.

Although several participants noted that the sport was the common and essential factor that brought individuals together, the sport in itself was not enough to create a sense of community. Connie (cycling) explained, "It started with sports, but then we would kind of get into conversations about what our majors were and what we were planning on doing afterwards. So it kind of started with sports, but then grew from there." That is, the common interest in sports needed to be combined with other unifying factors. As Dale (rowing) commented:

I think it's more than just rowing. It's more, because for me, the interest in rowing wasn't there initially. It was really an interest in pushing myself, and working hard, and getting in better shape. Also on the other side meeting new people, finding new challenges, everything like that. So, the common interest in rowing is definitely there, but there's definitely a lot more to it that creates a community.

Rather, a SOC was created for many of the participants when the common interest in a sport was accompanied by the pursuit toward a goal, shared values, strong commitment, or even a united frustration with something external to the group. Lucy (basketball) further explained why she felt she did not experience a SOC. "You can't garner a sense of community if you don't get along at all with each other. The only thing that a lot of us had in common was basketball, and that just wasn't enough." Lucy then went on to compare the sense of community she experienced in her role as a resident assistant (RA) with her university sports experience:

One of the differences is that the RAs always acted like they wanted to be there, and they were committed to what they were doing, and they enjoyed it. And, if you don't have those three things, I don't think that it's possible to kind of have that community-type atmosphere. If there's always internal conflict, it's really hard to build a community. And that's what it was like for basketball. You can't build a community like that. You really do need more than just an activity in common with them. You're not gonna build a sense of community with people that don't share the same morals and values, as you do.

In addition to the shared values and strong commitment that Lucy mentioned, other participants found that a common interest and rallying around the difficulties and inconveniences that their club teams faced fostered a SOC. Joan (soccer) stated:

The way that it was created a sense of community: we bonded over the fact that nobody cared about us. We had to do all 
this work, had crappy times for practices, and had to give up some of our weekends to travel. We had to drive our cars, and stuff like that, instead of having a bus and being provided travel. All those obstacles really bonded us.

\section{Damon (ultimate) added:}

It positively impacted the community and team, in that we had this unified force of being frustrated with the administration. We were consistently jealous of the support that the varsity sports would get when we would compare the amount of time we spent on our sport, and the personal investment. It seemed comparable, and they would get much more support and have lighter class workloads. We had a team full of engineers, scientists, and hard-core students, who would do a lot of class work, and then ultimate. It seemed unfair; however, it did things for our team, and it brought us together to know that we would work hard, and be a team, and stick together despite any disadvantages.

Overall, it was clear that a common interest was fundamental in creating a SOC, but that the common interest had to extend beyond just sports. Rather, sports had to be combined with a strong pursuit towards common goals, shared values, demonstration of a strong commitment, and/or uniting in response to an external obstacle in order to cultivate a SOC for the participants.

\section{LEADERSHIP OPPORTUNITIES}

The participation in directing and guiding the club in some manner was also a factor in creating SOC. As Philip (sailing) simply said, "Having leadership roles definitely provided a sense of community." Factors such as having a voice and decision-making influence, authority, and responsibility related to the club and its direction helped comprise Leadership Opportunities.
It's entirely student-run, it's just a cool experience. I felt so more connected to our team community as the president, because I hired the coach. I helped the coach, and I helped drive our truck to the races. Little things like that really make you think, Wow, this is not just practices that you show up at, and I could, peace out, and quit at any time. I'm an integral part of this community. And for me to keep doing this, I need to stay involved with the community, and the community needs me, as well. (Luke, crew)

As Luke articulated, when participants were able to actively demonstrate their role and purpose within the group through various leadership activities SOC was promoted.

Miles (lacrosse), when asked about the SOC he experienced, also elucidated the role of Leadership Opportunities. "Because it's all student-run and student-led ... we're the ones making the decisions on what direction we want to take the club. As an officer, and as a group of students, we decided things." Janet (waterpolo), a former varsity swimmer, also talked about how leadership opportunities impacted her SOC:

There's a lot of hard work that goes on behind the scenes in the club sports. With varsity sports, you just show up, and represent your university. With club sports, it's like I had to be on the phone calling referees. I was an officer one year, and so I was doing things that I normally that I wouldn't do as a varsity athlete. Whereas, varsity sports is: get on the bus and you are headed to compete. It's like just-show-upand-that's-it kind of thing. But, in club at the end of a tournament, we knew what went on behind the scenes. And that drew us closer, and also made us more proud of what we were able to do.

Taking on these leadership roles was at first a bit surprising to many of the participants, but overall it enhanced their SOC. As Marcus (baseball) expressed, "It's a little wary at first, 
for new participants that come in saying, 'Oh, it's all us.' You definitely have to step up in the leadership roles." And as Marcus and several of the others indicated, stepping into those leadership roles positively impacted their SOC. Mary (rugby) helped explain why leadership opportunities were important: "When you're in control, or have more control over what the club does, you feel more ownership and responsibility, and a greater sense of community."

The structure of sports clubs provided ample opportunity for participants to take on some type of leadership role, and the participants emphasized that this increased their SOC. In fact, all 21 participants referenced either a formal/designated leadership role (e.g., club president, officer, etc.) or informal leadership-type activities (e.g., arranging traveling, assisting in hiring coaches, organizing fundraisers). Furthermore, there was a cyclical nature in that the more an individual became part of a community, the more they sought out leadership opportunities.

\section{VOLUNTARY ACTIVITY}

Voluntary Activity was the third factor that emerged as creating a SOC. Voluntary Activity represents the idea that one was not forced nor pressured to be a part of the club or to show up at functions, but they continued their membership because they wanted to be there and were personally invested. "It was all strictly voluntary. You're accountable for yourself," Justin (tennis) claimed. Others echoed this sentiment and highlighted the self-motivation needed to participate in sports clubs. "It's very much on yourself" (Kelsey, waterpolo). "If you are going to participate in club sports, you have to find your own motivation for training and joining" (Jacob, waterpolo). Simply, showing up for practice with little or no external influence demonstrated a strong commitment to the group as well as the participants' love for their sport; it also played a vital role in creating a SOC. As Paul (tennis) summarized, it was "a good segue to bond, to be self-sufficient and responsible for your own community and club."

The participants further stressed the voluntary nature of their participation by referencing the absence of authority figures and the autonomy of the players. Miles (lacrosse) explained how this fostered a SOC with his team: "And we're gonna take it upon ourselves to work out on our own. It basically made us all kind of buy into it on our own level without just having someone tell us that." To give an additional example, Alice (lacrosse) stated:

A club sports athlete is doing it for the love the sport. The idea of being able to recreate and have that social network and that commitment and friendship, it is part of who we are. I think with a varsity athlete they have been pushed and pushed from parents to coaches to coaching staffs. ... We do it because we want to. For their whole lives they have had someone else direct their recreational activities. Someone else is telling them how to practice, what to lift, what to run, when to work out, what to eat. With a club sports athlete, if we want to succeed, we have self-control over it.

Mary (rugby) simply explained the importance of voluntary activity in fostering a SOC: "More of a sense of community was created because we were autonomous." The participants clearly expressed the importance of self-motivation, autonomy, and self-control in building an environment that promoted a SOC.

\section{COMPETITION}

The desire to excel in outperforming others and sharing the challenges and struggles inherent in sports emerged from the data as a contributor to SOC. This factor was named Competition 
and consisted of both internal and external rivalries. Interestingly and consistent with previous literature (e.g., Lambert \& Hopkins, 1995; Pretty \& McCarthy, 1991), there was a clear divide among the genders as to whether or not competition added to or detracted from a SOC. That is, the males noted that both internal and external competition enhanced the SOC they felt, while the females stressed that internal competition detracted from their SOC.

Justin (tennis) spoke of the role competition played in creating a SOC: "For me competition added to the sense of community. I mean, I'm a very competitive person. We wanted to succeed and win, and that helped with the bond and sense of community." All the males reiterated analogous thoughts in terms of competition positively contributing to a SOC. When Miles (lacrosse) was asked about whether or not he thought he experienced a stronger or weaker SOC in comparison to others, the impact of competition resonated in his response:

\begin{abstract}
We had a stronger sense of community because we were a highly competitive club. When you feel that there's something at stake, you develop that bond with each other. I think that competition does bring you together. Competition definitely bonded us together, because, we're playing at that level, because we love the game and want to win. But, definitely the level of competitiveness did impact the overall sense of community.
\end{abstract}

Luke (rowing) spoke of how competition both on and off the field was central to the SOC:

Our fund-raising activities were even competitive. We'd do these races and challenges. It was just an integral part of the experience-like who can do the math the quickest when you're selling hot dogs. We'd race each other up the stairs when we were picking up trash. The competition didn't end with the sport, and it improved the community.
It was clear that from the perspective of the males in this study that competition (internal and external) enhanced the SOC they experienced. Conversely, the females in this study tended to speak about how competition, specifically internal, detracted from the SOC. Tara (basketball) appropriately summarized the female participants' thoughts on the contribution competition makes to a SOC: "Competition within a club will definitely detract from the sense of community, but when you are competing against other schools it adds to it." When asked specifically why she felt competition detracted from her experience Sarah (lacrosse) responded, "These girls [her teammates] felt that they were better than everybody else. And they treated people that way."

While the females in the study appreciated some competition, it was clear that too much competition decreased the SOC. "I like where it's not like extremely competitive, but it's also not just messing around. If it was really competitive, then there would be a lot more bickering about playing time and stuff," Keisha (soccer) commented. Connie (cycling) reiterated this and the repercussions of too competitive of an environment for some females:

For me, the competition was positive. There were some situations where people were put into certain groups based on skill and they weren't happy about it. Except for a couple of women that were really competitive by nature, I think it detracted for most others. There were some women that I raced with that actually ended up not racing or dropped off the team because they just felt it was getting too competitive and they wanted to have fun.

While external competition had the capacity to add to the SOC for the females, unlike the males in this study, they were quick to emphasize the propensity for competition to detract. Lucy (basketball) explained: 
Anytime you get competitive females together, and you split them up on skill level, there's always gonna be griping. It's just the nature of people that tend to be competitive. In my experience it detracted from the sense of community. The competitiveness drives people to play better and work harder, but without the structure, which we lacked, the competitiveness just caused tension.

In summation, competition was emphasized as positively contributing to SOC for the males in this study; however, the females in this study were more likely to mention competition as detracting from SOC. While the females did welcome and seek out competition it was evident that too competitive of an environment negatively impacted the community. Interestingly, in the few instances where a female participant spoke positively about competition adding to the community, it was quickly tempered with thoughts and examples of how it also detracted, thus, positing that the role of competition is influenced by gender.

\section{DISCUSSION}

The results of this study reveal that Common Interest, Leadership Opportunities, Voluntary Activity, and Competition (moderated by gender) were the factors that created an environment in which university sports club participants experienced a SOC. This study further demonstrates that SOC is not a simply serendipitous outcome of sports. The appropriate environment, which should include these four salient factors, is essential for building and maintaining a strong SOC for sports club participants. These factors are not unique to sports. Other student activities would also benefit from understanding how these factors could work in concert to strengthen other university groups or clubs, and ultimately to improve the quality of life for a broader group of students.
While this is not necessarily surprising that Common Interest emerged as a salient factor in creating a SOC for sports club participantsone would expect that those in community would share some common interest-what is noteworthy is that the sport itself was not strong enough to create a SOC. Ideally, any extracurricular activity on a university campus should bring individuals together with a common interest, yet simply creating common interest groups are not enough: the initial attraction must be accompanied by other unifying factors. The participants in this study noted that common goals (e.g., winning a game or match), shared values, activities that demonstrate a strong commitment, and/ or uniting in response to an external obstacle were some of the supplement factors that built upon the initial common interest to create a strong SOC.

Voluntary Activity, comprised of the actions that went into participation with little to no external motivation, was also an intriguing finding. This idea of Voluntary Activity has not been noted in SOC studies outside of sports, yet it seems likely that it could be an overlooked factor in creating SOC in any context. Within the sports literature, Stevens's (2000) work supports the findings related to the role of Voluntary Activity in fostering a SOC. Stevens highlighted that the increased commodification and professionalization in women's hockey in Canada resulted in a decrease level of SOC for its participants. Stevens presented the "declining role of community in women's hockey as antagonisms grow between grassroots, high performance, and commercial forces" and further argued that the "acceleration of the sport into the Olympic Games has emphasized commerce and professionalism while at the same time undermined locality and voluntarism" (p. 123). It was clear that the shift towards a more elite and professional sport model led to a decline in 
the voluntary nature of the sport and resulted in a decrease in SOC experienced in women's hockey in Canada (Stevens, 2000). Our findings are similar: the voluntary nature of sports clubs is fundamental to fostering a SOC.

It was quite apparent that the participants in this study found a sense of pride in the fact that they were committed to their sport. The minimal barriers to entry and exit into a sports club fostered an environment of mutual trust and reciprocity. To an extent this created a self-selecting cycle, those who didn't buy in simply left, and those who were committed to the community remained. The voluntary nature of the sports clubs allowed members to demonstrate their commitment to the club and each other. In doing so, a trust and reciprocal commitment developed and a SOC was cultivated. This factor was not seen in Warner and Dixon's (2011) previous study with varsity athletes, indicating that there may be some critical difference in terms of how SOC develops within a peerdirected versus a more formalized coach- or administrator-directed model.

Leadership Opportunities and Competition were also revealed as factors in Warner and Dixon's (2011) study on SOC among NCAA varsity athletes. That is, the directing and guiding of activities that resulted in feelings of ownership and responsibility as well as the desire to outperform others were salient in both sports contexts. Thus, these factors were consistent in fostering a SOC in spite of the differences in structures. This indicates that Leadership Opportunities and Competition may be vital to creating SOC in any sports context; however, considering the life stage of the participants (18-23 years old) it may not be surprising that the participants were mindful of the Leadership Opportunities available to them. The literature asserts at this life stage the participants would have been becoming less dependent on their parents, would be making more independent decisions, and would be facing numerous social and relational challenges (Arnett, 2000). Therefore, the participants were likely experiencing this newly found independence and consequently were more attuned to leadership opportunities. Such opportunities provided the participants with a feeling of responsibility and ownership something that they may not have experienced prior to entering college and likely living on their own for the first time. The findings related to the importance of Leadership Opportunities are also consistent with servicelearning research (cf. Astin \& Sax, 1998; Bringle \& Hatcher, 1996; Schuh, Andreas, \& Strange, 1991). Administrators clearly should continue to seek out avenues that provide students with the opportunity to lead and direct their own experiences.

As noted, there also was a cyclical nature to Leadership Opportunities and community building; that is, the closer participants grew to a community, the more they sought out leadership opportunities — the more leadership opportunities they had, the greater the SOC. This continuing pattern helped sustain and strengthen the community.

Providing Leadership Opportunities and relinquishing this "control" is certainly not a new idea in sports. Kleiber (1983) asserted, "The ultimate potential of sport for self-development and sociocultural evolution may require then that control be returned to the players, at least to a greater degree" ( $p$. 92). Leadership Opportunities and this idea of distributing responsibilities and control back to the participants will foster a greater SOC, but currently does not seem to be a priority when administering sports. In fact, the organizational control of many modern sports may impede the development of a SOC for the participants. "By 'relieving' participants of the responsibility for maintaining the integrity of the social structures that supports their 
activities, organizational control diminishes the interrelatedness of competitors" (Kleiber, 1983 , p. 91); that is, too much organization may be detrimental to the participants and the ensuing SOC that ideally would develop. Jacob (waterpolo) highlighted how within the sports club structure, SOC was imperative for the club to survive because the control rests in the participants' hands:

I think it would have been hard, and it would have been unlikely that people could go through 4 years of a playing in a successful club sports program without a successful sense of community. Everyone has to do their part, practices have start on time, trips have to be scheduled, dues have to be paid. Everyone has a job to do.

Knowing the many life quality-enhancing benefits for individuals who experience a SOC, but especially considering that SOC is associated with reduced incidences of student burnout and improvements in academic performance (McCarthy et al., 1990), university sports administrators in particular should reconsider the significance of having leadership opportunities available to all the participants, such that they might experience the benefits of SOC.

If there is a renewed interest in the play values of sport, in the immediate experience, the relationships, and the process instead of so completely in winning and losing, and if control is substantially returned to the participants, the potential of sport for personal transformation and community building can conceivably be restored. (Kleiber, 1983, p. 91)

Consequently, it is imperative that future research continue to explore the role of Leadership Opportunities in fostering a SOC in both sports and university contexts.

Competition and the gender differences (i.e., competition positively impacted SOC for males and negatively impacted SOC for females) that emerged from the data were also consistent with previous findings. Specifically, these results supported Pretty and McCarthy's (1991) and Warner and Dixon's (2011) research that suggested that gender differences likely exist in terms of how Competition impacted SOC. The fact that Competition varied by gender is likely a result of the socialization process. That is, typically males and females are socialized differently and therefore act according to the norms and values that are transmitted to them as being gender appropriate (Dixon, Warner, \& Bruening, 2008; Gneezy \& Rustichini, 2004). This rationale for the gender differences regarding Competition are supported by Gneezy, Leonard, and List's (2006) experimental study, which revealed that competitiveness observed between genders varied based on the environment and cultural setting. This suggests that the gender differences that emerged related to Competition are likely an artifact of American cultural norms and values as they relate to gender and sports.

Competition (and the gender differences) was also found in Warner and Dixon's (2011) study as a factor contributing to varsity athletes' SOC. A noteworthy difference is that the sports club participants mentioned both internal and external rivalries, whereas the varsity athletes (both sexes) tended to view competition solely in terms of the internal competition that existed; that is, sports club participants mentioned both rivalries within their team and against other teams, while the varsity participants focused more on the rivalries within their team. The mere presence of athletic scholarships and the recruiting process at the varsity level may explain this difference. Without a financial stake or coach's judgment tied to participation and success, internal and external competition may become equally prominent for sports club athletes. For varsity athletes scholarships and the opportunity to play are not always guaranteed 
for 4 years, and although there are some NCAA regulations in place to protect varsity athletes, Warner and Dixon's (2011) work revealed that a fear still exists that funding or the opportunity to play could be taken away. This may explain why internal competition was more prominent among varsity athletes. Considering the gender differences that were found in terms of how Competition impacted SOC, this nuance between the different intercollegiate sports system structures should be further explored. In terms of Competition, the varsity model may be fostering a SOC for males, but not for females. Further exploration of this factor may provide critical insight into the retention of female athletes.

\section{IMPLICATIONS AND CONCLUSIONS}

This study contributes to both practice and theory in a number ways. First in terms of practice, recreational and non-revenuegenerating sports on university campuses will continue to face the challenges of justifying their existence, especially when universities are faced with budget cuts. For this inquiry we considered the historical significance and rationale of sports on university campuses (Brubacher \& Rudy, 1997; Chu, 1989; Smith, 1988); in doing so, we highlighted one of the most common justifications of sports on university campuses: to create a SOC for its participants. By focusing on how and when a SOC is experienced for participants, this study provides practical information for administrators that will aid in justifying and legitimatizing the importance of sports and extracurricular activities on campuses. While the focus of this research was on sports clubs, all clubs and organizations could benefit from a better understanding of the factors observed to foster SOC. The factors revealed in this study are not unique to sports and should be considered by all administrators hoping to improve the student life experience.

In many cases, sports is already creating a SOC for participants and the structures are in place to continue to do so. This study highlights Common Interest, Leadership Opportunities, Voluntary Activity, and Competition as the most salient factors impacting SOC for sports club participants on university campuses. Administrators need to be aware of these factors so that they can continue to encourage participants appropriately and assist in structuring sports programs in such a manner that these components are present. For example, it was clear that Leadership Opportunities was imperative in creating a SOC. When structuring sports programs, administrators need to realize the value of creating leadership opportunities for all of their participants, not just a few. Again, simply giving the participants control in directing their experience was essential to creating a SOC. For example, having a voice in the hiring of coaches, directing fundraisers, and organizing travel were just some of the leadership opportunities that resonated with the participants in terms of fostering a SOC.

To give another example, the data related to Competition also has many practical applications. This study supported that internal competition negatively impacted SOC for female participants, but positively impacted SOC for male participants. Thus, a focus on personal goals and the mastering of skills, rather than creating interteam rivalries that pit teammates against one another, would be most beneficial for enhancing the SOC for females. In contrast, such interteam rivalries would likely improve the SOC for male participants. Overall, the practical implications of this study are clear: knowing what and how a SOC is created provides administrators with the necessary knowledge that will aid in fostering a SOC for sports participants. 
Finally, this study contributes to SOC and sports management theory. First, it challenges the foundational SOC theory originally posited by McMillan and Chavis (1986). Although their SOC theory continues to be widely accepted and acknowledged in the community psychology literature (Chipuer \& Pretty, 1999), this study suggests that Competition and Voluntary Activity are factors worthy of future consideration and exploration when evaluating SOC. McMillan and Chavis neither addressed nor alluded to either of these components. The data from this study suggests that these two components should be probed when evaluating SOC in other settings.

Second, based on this study and Warner and Dixon's (2011) work it is likely that Competition and Leadership Opportunities would be two considerable components of a more specific sports and SOC theory. This nascent line of research represents an opportunity for researchers and administrators. Rather than relying on the assumption that sports participation serendipitously creates community, this study challenges that thought, revealing four factors that contribute to creating a SOC and providing evidence that life quality can be enhanced by the benefits of SOC.

Considering the noteworthy decline in social connectedness and increase in social isolation both on campuses and in American society in general (McPherson et al., 2006; Putnam, 2000), this research is also timely in that it provides a great opportunity for university administrators to lead the way in seeing that these trends are reversed. Through understanding how and when a SOC is created in a sports context, university administrators can positively impact the lives of participants by designing environments that cultivate a SOC. Again, the factors highlighted in this study are not necessarily unique to sports, and thus should be carefully considered when advising all club and organization leaders. In an effort to maximize the potential benefit of extracurricular activities on university campuses, research should continue to challenge the existing SOC theories and build upon this work.

Correspondence concerning this article should be addressed to Stacy Warner, East Carolina University, Department of Kinesiology, 173 Minges Coliseum, Greenville, NC 27858; warners@ecu.edu, stacymwarner@gmail.com

\section{REFERENCES}

Arnett, J. J. (2000). Emerging adulthood: A theory of development from the late teens through the twenties. American Psychologist, 55, 469-480.

Astin, A. W., \& Sax, L. J. (1998). How undergraduates are affected by service participation. Journal of College Student Development, 39, 251-263.

Bachrach, K. M., \& Zautra, A. J. (1985). Coping with a community stressor: The threat of a hazardous waste facility. Journal of Health and Social Behavior, 26, 127-141.

Battistich, V., \& Hom, A. (1997). The relationship between students' sense of their school as a community and their involvement in problem behaviors. American Journal of Public Health, 87, 1997-2001.

Benzies, K. M., \& Allen, M. N. (2001). Symbolic interactionism as a theoretical perspective for multiple method research. Journal of Advanced Nursing, 33, 541-547.
Berkman, L. F., Glass, T., Brissette, I., \& Seeman, T. E. (2000). From social integration to health: Durkheim in the new millennium. Social Science \& Medicine, 51, 843-857.

Bess, K. D., Fisher, A. T., Sonn, C. C., \& Bishop, B. J. (2002). Psychological sense of community: Theory, research and application. In A. T. Fisher, C. C. Sonn, \& B. J. Bishop (Eds.), Psychological sense of community: Research, applications, and Implications (pp. 3-22). New York, NY: Kluwer Academic/Plenum.

Boyer, E. (1990). Campus life: In search of community. Princeton, NJ: The Carnegie Foundation for Advancement of Teaching.

Bringle, R. G., \& Hatcher, J. A. (1996). Implementing service learning in higher education. Journal of Higher Education, 67, 221-239

Brubacher, J. S., \& Rudy, W. (1997). Higher education in transition: A history of American colleges and universities (4th ed.). New Brunswick, NJ: Transaction Publishers. 
Camp, W. C. (1885). College athletics: Youth the time for physical development. New Englander, January, 138-140.

Chalip, L. (2006). Toward a distinctive sport management discipline. Journal of Sport Management, 20, 1-21.

Chavis, D. M., \& Wandersman, A. (1990). Sense of community in the urban environment: A catalyst for participation and community development. American Journal of Community Psychology, 18, 55-81.

Chipuer, H., \& Pretty, G. (1999). A review of the Sense of Community Index: Current uses, factor structures, reliability, and further development. Journal of Community Psychology, 27, 643-658.

Chu, D. (1989). The character of American higher education and intercollegiate sports. Albany, NY: State University of New York Press.

Davidson, W., \& Cotter, P. R. (1991). The relationship between sense of community and subjective well-being: A first look. Journal of Community Psychology, 19, 246-253.

Deneui, D. (2003). An investigation of first-year college students' psychological sense of community on campus. College Student Journal, 37, 224-235.

Dixon, M. A., Warner, S. M., \& Bruening, J. E. (2008). More than just letting them play: The enduring impact of parental socialization on female sport involvement. Sociology of Sport Journal, 25, 538-559.

Gneezy, U., \& Rustichini, A. (2004). Gender and competition at a young age. American Economic Review Papers and Proceedings, 94(2), 377-381.

Gneezy, U., Leonard, K. L., List, J. A. (2006). Gender differences in competition: The role of socialization. Unpublished manuscript, University of Chicago, IL.

Gusfield, J. R. (1975). The community: A critical response. New York, NY: Harper Colophon.

Hess, L. A. (1971). Institutional commitment to the financing of sports club programs. Journal of Health, Physical Education, and Recreation, 42, 24.

Hill, J. (1996). Psychological sense of community: Suggestions for future research. Journal of Community Psychology, 24, 431-438.

Hirschi, T. (1969). Causes of delinquency. Berkeley, CA: University of California Press.

Hyatt, R. W. (1977). Intramurals sports: Organization and administration. Saint Louis, MO: C. V. Mosby.

Jacob, E. (1987). Qualitative research traditions: A review. Review of Educational Research, 57, 1-50.

Kleiber, D. (1983). Sport and human development: A dialectical interpretation. Journal of Humanistic Psychology, 23, 76-95.

Lambert, S., \& Hopkins, K. (1995). Occupational conditions and workers' sense of community: Variation by gender and race. American Journal of Community Psychology, 23, 151-179.

Larkin, M., Watts, S., Clifton, E. (2006). Giving voice and making sense in Interpretative Phenomenological Analysis. Qualitative Research in Psychology, 3(2), 102-120.

Lewis, G. (1970). The beginning of organized collegiate sport. American Quarterly, 22, 222-229.

Luschen, G. (1986). The practical uses of sociology of sport: Some methodological issues. In C. R. Rees \& A. W. Miracle, (Eds.). Sport and social theory (pp.149-157). Champaign, IL: Human Kinetics.

Lyons, K., \& Dionigi, R. (2007). Transcending emotional community: A qualitative examination of older adults and masters' sports participation. Leisure Sciences, 29, 375-389.
McCarthy, M., Pretty, G., \& Catano, V. (1990). Psychological sense of community: An issue in student burnout. Journal of College Student Personnel, 31, 211-216.

McCormack, J. B., \& Chalip, L. (1988). Sport as socialization: A critique of methodological premises. Social Science Journal, 25, 83-92.

McMillan, D., \& Chavis, D. (1986). Sense of community: A definition and theory. Journal of Community Psychology, 14, 6-23.

McPherson, M., Smith-Lovin, L., \& Brashears, M. E. (2006). Social isolation in America: Changes in core discussion networks over two decades. American Sociological Review, 71, 353-375.

Miles, M., \& Huberman, A. (1994). Qualitative data analysis. Thousand Oaks, CA: SAGE.

Mitrano, J., \& Smith, R. (1990). The socioemotional functions of sport and the maintenance of community: Hurricane Hugo and horse racing in St. Croix. Arena Review, 14, 47-58.

Munhall, P. L. (2007). Nursing research: A qualitative perspective (4th ed.). Sudbury, MA: Jones and Barlett.

NVivo (Version 8) [Computer software]. Burlington, MA: QSR International.

Obst, P., Zinkiewicz, L., \& Smith, S. (2002a). Sense of community in science fiction fandom, part 1: Understanding sense of community in an international community of interest. Journal of Community Psychology, 30, 87-103.

Obst, P., Zinkiewicz, L., \& Smith, S. (2002b). Sense of community in science fiction fandom, part 2: Comparing neighborhood and interest group sense of community. Journal of Community Psychology, 30, 105-117.

Pretty, G., Andrewes, L., \& Collett, C. (1994). Exploring adolescents' sense of community and its relationship to loneliness. Journal of Community Psychology, 22, 346-358.

Pretty, G., \& McCarthy, M. (1991). Exploring psychological sense of community among men and women of the corporation. Journal of Community Psychology, 19, 351-361.

Puddifoot, J. E. (1996). Some initial considerations in the measurement of community identity. Journal of Community Psychology, 24, 327-336.

Putnam, R. D. (2000). Bowling alone: The collapse and revival of American community. New York, NY: Simon and Schuster.

Sandelowski, M. (1993). Theory unmasked: The uses and guises of theory in qualitative research. Research in Nursing \& Health, 16, 213-218.

Sarason, S. B. (1974). The psychological sense of community: Prospects for a community psychology. San Francisco, CA: Jossey-Bass.

Schimmel, K. S. (2003). Sport. In Karen Christensen \& David Levinson (Eds.), Encyclopedia of community: From village to virtual world (pp. 1334-1336). Thousand Oaks, CA: SAGE.

Schuh, J. H., Andreas, R. E., \& Strange, C. C. (1991). Students at metropolitan universities: Viewing involvement through different lenses. Metropolitan Universities 2, 64-74.

Smith, R. A. (1988). Sports and freedom: The rise of big-time college athletics. New York, NY: Oxford University Press.

Stevens, J. (2000). The declining sense of community in Canadian women's hockey. Women in Sport \& Physical Activity Journal, 9(2), 123-140.

Warner, S., \& Dixon, M. A. (2011). Understanding sense of community from the athlete's perspective. Journal of Sport Management, 25, 257-271. 